\title{
Study of stress and depression among students specialty "nurse" in the medical university of Plovdiv before the session.
}

\author{
Okean Kostov $^{1 *}$, Diana Paskaleva ${ }^{1}$, Stoilka Tufkova ${ }^{2,3}$, Maria Bozhkova ${ }^{4}$, Boris Kuzmanov ${ }^{5}$ \\ ${ }^{1}$ Department of Nursing Care, Faculty of Public Health, Plovdiv Medical University, Plovdiv, Bulgaria \\ ${ }^{2}$ Medical Simulation Training Center, Plovdiv Medical University, Plovdiv, Bulgaria \\ ${ }^{3}$ Second Internal Department, Toxicology Section, Plovdiv Medical University, Plovdiv, Bulgaria \\ ${ }^{4}$ Medical College, Faculty of Public Health, Plovdiv Medical University, Plovdiv, Bulgaria \\ ${ }^{5}$ Department of Midwifery Care, Plovdiv Medical University, Plovdiv, Bulgaria
}

\begin{abstract}
Purpose: To assess the level of stress, the sources of stress and the spread of depression among students of "nurse" specialty Medical University-Plovdiv.

Methods: Cross-sectional survey in 2017, featuring 60 freshman and 40-students from "nurse" specialty in the third course. The relationship between the variables is assessed using chi-square test with a significance level of $\mathbf{p}<\mathbf{0 . 0 5}$. The statistical analysis in the survey includes descriptive statistic (average value and standard deviation), chi-square test for evaluation of the correlations between the stress-level and depression and demographic dates (correlations coefficient of Pearson and Kendal) and t-test (Welch two sample t-test).

Results: Moderate to very severe stress is observed in $\mathbf{7 8 . 4 \%}$ of the surveyed students. Depressive symptoms were also $54.7 \%$ of respondents (mild depression in $41.7 \%$, moderate in $11.5 \%$, severe in $1.4 \%)$. There is no significant difference in depression between the first and third-course nurses $(\mathbf{p}=0.1613)$ and in men and women $(p=0.85)$.

Conclusion: Academic-related stressors are a major cause of stress to students in the both courses. We recommend the conducting of further surveys on stress and depression in all specialties of medical universities in Bulgaria and the implementation of programs for managing stress.
\end{abstract}

Keywords: Nurse student specialty, Stressors, Depression, Becks inventory.

Accepted on May 22, 2018

\section{Introduction}

According to a lot of studies is the teaching in the medical universities with considerable stress connected [1-5]. The distress by "nurse" student specialty shows in many ways like burnout, anxiety, depression [6-10].

Significant survey of stress by Compton et al. [2] and the related therefore depression during the medical education covers the student in different medical universities and shows startle dates about the psychical status of the students. A lot of studies in different countries have estimated that the depression among the students in a medical university appears often ant is in a more heavy stage than that among people of the same age in the common population [11-17].

The high level of stress and depression could drive to abuse with substances, suicide thoughts and lead to commit suicide, growth of cynicism, influence of the patients care and change for the worse of the life quality [2,18-24]. The students in the medical universities suffering on depression are often thinking to break their studies $[13,25]$.

\section{Methods}

For testing the physical health of the students in the Department of Nursing and Midwifery Care, Faculty of Public Health, MU of Plovdiv a cross-sectional survey is in 2017 carried out by 60 freshman (55 women) and 40-students from "nurse" specialty in the third course.

A questionnaire, created especially for this reason, was used. Answers on this questionnaire have been given by $90.9 \%$ from the freshman $(150 / 165)$ and $75.3 \%$ by student in the third course $(128 / 170)$.

To survey the stress-factors a short version of the Questionnaire for stressors with 20 questions was applied by students of "nurse" specialty [26]. 
The Beck depression inventory-BDI with 21 questions was applied to examine the depression. This is a reliable and valid instrument widespread used for the valuation of authority of the depressions symptoms [27].

The statistical analysis in the survey includes descriptive statistic (average value and standard deviation), chi-square test for evaluation of the correlations between the stress-level and depression and demographic dates (correlations coefficient of Pearson and Kendal) and t-test (Welch two sample t-test).

\section{Results}

From all 100 students, taking part in the survey, 98\% are women, $31 \%$ have parents with medical education and $62.6 \%$ have an intimate partner. Moderate to strong stress is obtained by $78.4 \%$ from the students in the specialty "nurse", while strong and high-strong stress is from $20.1 \%$ of the respondents declared.

$21.4 \%$ of the women and $3.2 \%$ of the men in this survey convey about strong or very severe stress, as statistic significant relation between stress and sex has been observed $(p=0.004)$. But between stress and educations course a significant relation is missing $(\mathrm{p}=0.426)$.

Academic-related stressors are a major cause of stress. They cause strong and very severe stress to $59.7 \%$ of the surveyed students. 6 from top 10 stressors among students of "nurse" specialty in this survey are academic connected. As leading cause for stress are pointed the tests and examinations as they put to moderate or very severe stress to $84.2 \%$ of the surveyed students.

The dates analyses on depression show that the depressive symptoms are observed by $54.7 \%$ of all surveyed students. There isn't significant relation between depression and educations course $(\mathrm{p}=0.163)$, as between depression and sex $(p=0.85)$. But there is a significant connection between the stress and the depression $(\mathrm{r}=0.46 ; \mathrm{p}<0.001)$.

\section{Discussion}

The survey shows us, that moderate to severe stress was observed by $78.4 \%$ students of the "nurse" specialty. This result is similar to other investigations on stress by students in the medical universities, according that is their distress high and varies from 21 to $56 \%$ [28-31].

The dates of this survey aren't collected during the session. Therefore could the academic-related stressors cause even stronger stress, if the survey was provided right next to the examinations; the high level of academic stress could be relieved through consideration of the changes in the educational programs and loadings.

In our survey are the depressive symptoms obtained by $54.7 \%$ of the student in this specialty. This result is similar to the established in other surveys on depression, carried out abroad.

The review of the available levels shows, that the depression among the students ranges from 12 to $71 \%$. The differences in the fixed levels of depression could be explained by the different used instruments of screening.

Comparing the results of our study with a similar study of medical students in MU-Sofia percentages $63.2 \%$ are almost the same with our $54.7 \%$ [32].

This percentage is higher than that reported in other studies of depression in students of medicine in Central and Eastern Europe.

According to the literature, the prevalence of depressive symptoms among medical students in England and Englishspeaking countries in Europe 6.0-66.5\% [32,33].

In Central and Eastern Europe have been several studies of depression in medical students. In Poland, 56.32\% of medical students are set depressive symptoms, and in Germany $34.92 \%$ [34].

According to another study, $13.1 \%$ of German medical students showed slight and $5.8 \%$ clinically significant depressive symptoms [35].

In Bosnia and Herzegovina was established mild depression at $41.4 \%$ and moderate in $17.9 \%$ of medical students [36].

In Macedonia, $10.4 \%$ of medical students had depression [37], Serbia 22.5\% [38], Estonia 30.6\% [39] and Lithuania 14\% [40].

As in other surveys, our investigation detected association between stress and depression [29,30]. By the analysis of the possible protective and risks factors of depressions growth is an interesting relationship detected. The absence of parents with medical education correlates with depressive symptoms by students-freshmen, but similar connection is missing by students in the third course.

It is possible the children of people with medical education to be better prepared to the academic challenges of the education. Probably, bit by bit, abilities to cope with difficulties are build, which could explain the missing of correlation by the students in the third course. It is advisable to lead future surveys on the influence of family-and social support by depression.

Many from the respondents in this survey express wish to courses in psychological health and to be a mentor [31]. Their connection to the depression shows the necessarily of theirs initiation in our medical universities.

This survey hasn't shackles. The excerpt is relevant to students-freshman and third course students of "nurse" specialty in one university in the land. Therefore the results can't be generalized to all students of "nurse" specialty. With this survey we have tested only the depressive symptoms, obtained during the last two weeks. We haven't collect information to depressive episodes in the past or to familyoverburden with depression.

In the present survey aren't render an account of the role of personal life-events (illness, death of family-member, marriage, birth etc.) and the role of financial problems as possible reasons to stress. 


\section{Conclusion}

The dates of this survey point to necessity of initiation the programs of stress-management in to Bulgarian medical education. For more clarity we recommend to be carried out future investigations on stress and depression to students from all medical specialties in Bulgaria.

From this literature review can be concluded that the incidence of depression in medical students at the Medical Faculty of Sofia and Faculty of Public Health, MU-Plovdiv is greater than in other countries of Central and Eastern Europe.

In conducting this study, we supplement the knowledge of mental health of medical students in Bulgaria. This is the first study in Central and Eastern Europe on the role of misuse of medical students as a possible risk factor for depression. In conclusion, we recommend the introduction of prevention programs for the mental health of medical students, as well as providing access to psychological counselling and assistance.

\section{References}

1. Miller P. The first year at medical school, some findings and students perceptions. Med Educ 1994; 28: 5-7.

2. Compton M, Carrera J, Frank E. Stress and depressive symptoms/dysphoria among US medical students: results from a large, nationally representative survey. J Nerv Ment Dis 2008; 196: 891-889.

3. Supe A. A study of stress in medical students at Seth GS medical college. J Post Graduate Med 1998; 44: 1-6.

4. Foster-Williams K, Thomas P, Gordon A. An assessment of stress among clinical medical students of the University of the West Indies, Mona Campus. West Indian Med J 1996; 45: 51-54.

5. Lloyd C, Gartrell N. Psychiatric symptoms in medical students. Comprehensive Psychiatr 1984; 225: 552-565.

6. Dahlin M, Joneborg N, Runeson B. Stress and depression among medical students: a cross-sectional study. Med Educ 2005; 39: 594-604.

7. Dyrbye L, Thomas M, Shanafelt T. Systematic review of depression anxiety, and other indicators of psychological distress among U.S. and Canadian medical students. Acad Med 2006; 81: 354-373.

8. Guthrie E, Black D, Shaw C. Embarking upon a medical career: psychological morbidity in first year medical students. Med Educ 1995; 29: 337-341.

9. Moffat K, McConnachie A, Ross S. First year medical student stress and coping in a problem-based learning medical curriculum. Med Educ 2004; 38: 482-491.

10. Tyssen R, Vaglum P, Gronvold N. Factors in medical school that predict postgraduate mental health problems in need of treatment. A nationwide and longitudinal study. Med Educ 2001; 35: 110-120.

11. Aktekin M, Karaman T, Senol Y. Anxiety, depression and stressful life events among medical students: a prospective study in Antalya, Turkey. Med Educ 2001; 35: 12-17.
12. Guthrie E, Black D, Bagalkote H. Psychological stress and burnout in medical students: a five-year prospective longitudinal study. J R Soc Med 1998; 91: 237-243.

13. Clark D, Zeldow P. Vicissitudes of depressed mood during four years of medical school. JAMA 1988; 260: 2521-2528.

14. Rosal M, Ockene I, Ockene J. A longitudinal study of students' depression at one medical school. Acad Med 1997; 72: 542-546.

15. Carson A, Dias S, Johnston A. Mental health in medical students: a case control study using the 60 item General Health Questionnaire. Scott Med J 2000; 45: 115-116.

16. Rosenthal J, Okie S. White coat, mood indigo-depression in medical school. N Engl J Med 2005; 353: 1085-1088.

17. Zoccolillo M, Murphy G, Wetzel R. Depression among medical students. J Affect Disord 1986; 11: 91-96.

18. Tyssen R, Vaglum P, Gronvold N. Suicidal ideation among medical students and young physicians: a nationwide and prospective study of prevalence and predictors. J Affect Disord 2001; 64: 69-79.

19. Paro H, Morales N, Silva C. Health-related quality of life of medical students. Med Educ 2010; 44: 227-235.

20. Schernhammer E. Taking their own lives: the high rate of physician suicide. NEJM 2005; 352: 2473-2476.

21. Hull S, Di Lalla L, Dorsey J. Prevalence of health-related behaviors among physicians and medical trainees. Acad Psychiat 2008; 32: 31-38.

22. Dyrbye L, Thomas M, Shanafelt T. Medical student distress: causes, consequences, and proposed solutions. Mayo Clin Proc 2005; 80: 1613-1622.

23. Dyrbye L, Thomas M, Massie F. Burnout and suicidal ideation among US medical students. Ann Intern Med 2008; 149: 334-341.

24. Flaherty J, Richman J. Substance use and addiction among medical students, residents and physicians. Psychiatr Clin North Am 1993; 16: 189-197.

25. Dyrbye L, Thomas M, Power D. Burnout and serious thoughts of dropping out of medical school: a multiinstitutional study. Acad Med 2010; 85: 94-102.

26. Yusoff M, Yen Yee L, Heng Wei L. A study on stress, stressors and coping strategies among Malaysian medical students. Int J Students' Res 2011; 1: 45-50.

27. Beck A, Steer R, Garbin M. Psychometric properties of the Beck Depression Inventory Twenty-five years of evaluation. Clin Psych Rev 1988; 8: 77-100.

28. Firth J. Levels and sources of stress in medical students. Br Med J Clin Res Ed 1986; 292: 1177-1180.

29. Mikolajczyk R, Maxwell A, Naydenova V. Depressive symptoms and perceived burdens related to being a student: Survey in three European countries. Clin Pract Epidemiol Ment Health 2008; 4: 19.

30. Baldassin S, Alves T, de Andrade A, Martins L. The characteristics of depressive symptoms in medical students during medical education and training: a crosssectional study. BMC Med Educ 2008; 8: 60. 
31. Georgieva E. Mentoring in the medical education. Praemedicus 1925; 29: 23-27.

32. Georgieva E. Depressive symptoms in medical students studying in Medical University-Sofia. Albanian Med J 2014; 3: 7-13.

33. Haldorsen, H, Bak NH, Dissing A, Petersson B. Stress and symptoms of depression among medical students at the University of Copenhagen. Scand J Public Health 2014; 42: 89-95.

34. Seweryn M, Tyrała K, Kolarczyk-Haczyk A, Bonk M, Bulska W, Krysta K. Evaluation of the level of depression among medical students from Poland, Portugal and Germany. Psychiatr Danub 2015; 27: 216-222.

35. Jurkat HB, Richter L, Cramer M, Vetter A, Bedau S, Leweke F, Milch WN. Depression and stress management in medical students. A comparative study between freshman and advanced medical students. Nervenarzt 2011; 82: 646-652.

36. Sakić M, Martinac M, Skobić H, Jakovljević M. Depression among students of the medical faculty and doctors in Mostar. Med Arh 2005; 59: 19-22.

37. Mancevska S, Bozinovska L, Tecce J, PluncevikGligoroska J, Sivevska-Smilevska E. Depression, anxiety and substance use in medical students in the Republic of Macedonia. Bratisl Lek Listy 2008; 109: 568-572.
38. Dragana R-I, Darko H, Mihajlo J, Kostas F, Marianna S, Nemanja R. A ten-year study of depressive symptoms in Serbian medical students. Acta Clin Croat 2013; 52: 157-163.

39. Eller T, Aluoja A, Vasar V, Veldi M. Symptoms of anxiety and depression in Estonian medical students with sleep problems. Depress Anxiety 2006; 23: 250-256.

40. Bunevicius A, Katkute A, Bunevicius R. Symptoms of anxiety and depression in medical students and in humanities students: relationship with big-five personality dimensions and vulnerability to stress. Int $J$ Soc Psychiatry 2008; 54: 494-501.

\section{*Correspondence to}

Okean Kostov

Department of Nursing Care

Faculty of Public Health

Plovdiv Medical University

Plovdiv

Bulgaria 